\title{
Intercellular transmission of endoplasmic reticulum stress through gap junction targeted by microRNAs as a key step of diabetic kidney diseases?
}

\author{
Mitsuo Kato^$^{\wedge}$ \\ Department of Diabetes Complications and Metabolism, Arthur Riggs Diabetes \& Metabolism Research Institute, Beckman Research Institute of \\ City of Hope, Duarte, CA, USA \\ Correspondence to: Mitsuo Kato. Arthur Riggs Diabetes \& Metabolism Research Institute, Beckman Research Institute of City of Hope, Duarte, CA \\ 91010, USA. Email: MKato@coh.org.
}

Submitted Mar 19, 2021. Accepted for publication Mar 30, 2021.

doi: $10.21037 /$ atm-21-1280

View this article at: http://dx.doi.org/10.21037/atm-21-1280

Diabetic kidney disease (DKD) is a type of renal diseases caused by Diabetes Mellitus (1-4). Renal fibrosis and hypertrophy by accumulated extracellular matrix (ECM) proteins in glomerular and tubular compartments, as well as podocyte dysfunction and related albuminuria are major features of DKD. Metabolic changes such as mitochondrial dysfunction, oxidative stress, endoplasmic reticulum stress (ERS) and loss of autophagy in renal cells are also associated with progressive DKD (4-7). Noncoding RNAs including microRNAs (miRNAs) and longnon-coding RNAs (lncRNAs) are now very attractive regulators of gene expression because of their no proteincoding potential and because miRNAs regulate cellular functions and pathophysiological conditions related to human disease including DKD by down-regulating their specific targets $(4,8-11)$.

A recent report by Li et al. showed that miR-30 family members (miR-30s) directly target connexin 43 (Cx43) (12), a Gap junction protein which mediates cell-cell transmission of ions, signaling molecules, metabolites and nucleic acids $(13,14)$. The decrease of miR-30s induces Cx43 which enhances ERS-related caspase 12 and apoptosis in cultured podocytes treated with high glucose conditions (HG) and in kidneys from diabetic rats (Figure $1 A$ ). Silencing of $\mathrm{Cx} 43$ by siRNAs inhibited ERS and apoptosis induced by HG in podocytes. $\mathrm{Cx} 43$ has been suggested as molecular target of kidney diseases and activates ERS (15-18). The authors also showed that adeno-associated virus (AAV)-mediated induction of miR-30s ameliorated kidney injury in diabetic rats, suggesting that miR-30s/Cx43/ERS axis may be a new potential target for DKD.

On the other hand, another recent paper reported that ERS can be transmitted from cell to cell through Cx43 and spreading ERS may cause liver diseases and problems such as insulin resistance (19). Therefore, global spread of ERS through Gap junction (Cx43) may also contribute to the injury and death of podocytes (and even other renal glomerular cells) (Figure 1B). Thus, the event is not simply happening in single cells but local ERS in single cells may be spread into multiple adjacent cells and cause global increase of ERS in kidney glomeruli (not only in podocytes) and eventually lead to kidney injury (Figure 2).

Although the molecular mechanisms of miR-30s reduction by HG in podocytes are not clear (12), Gap junction may also explain how miR-30s levels were reduced, because transmission of miR-30s from healthy cells to stressed cells may dilute the intracellular concentration of miR-30s (Figure 1B). While miRNAs usually control target gene expression (8), endogenous RNAs also control miRNAs by target RNA-directed miRNA degradation (TDMD) (20-22). Recent reports have demonstrated the strong evidence of TDMD (22-25) and miR-30s have been reported as one of such miRNAs subjected to TDMD (25). Although it is depending on the members, at least miR-30b/c

\footnotetext{
^ ORCID: 0000-0002-1783-1084.
} 
A

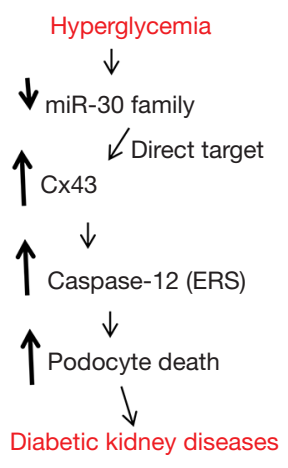

B

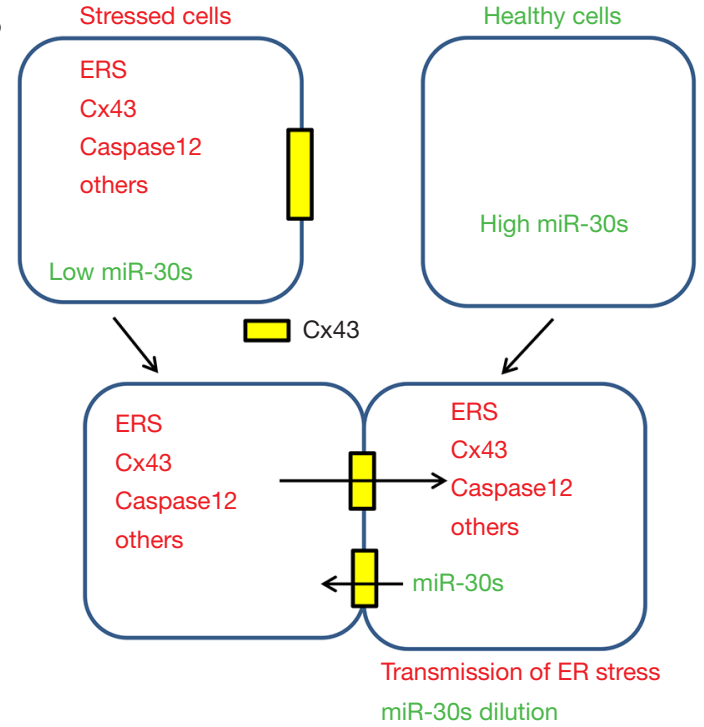

Figure 1 Mechanisms of ERS activation and cell-cell transmission via Cx43. (A) A model for the pathogenesis of DKD through miR-30/ Cx43/ERS. (B) Possible intercellular transmission of ERS (also Caspase12, Cx43, miR-30s and others) between stressed cells and healthy cells through $\mathrm{Cx} 43$. Please read the main text for more details. ERS, endoplasmic reticulum stress; Cx43, connexin 43; DKD, diabetic kidney disease; miR-30s, miR-30 family members.

A

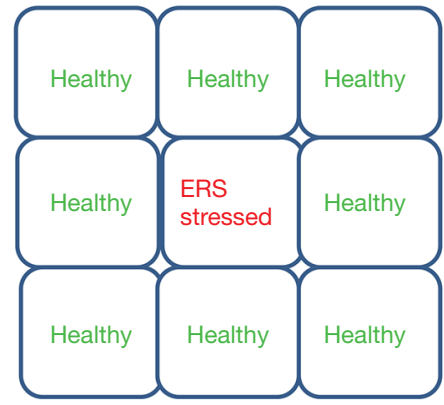

Local (single cell) ERS.

High miR-30 family

Low Cx43

No transmission

Healthy kidney

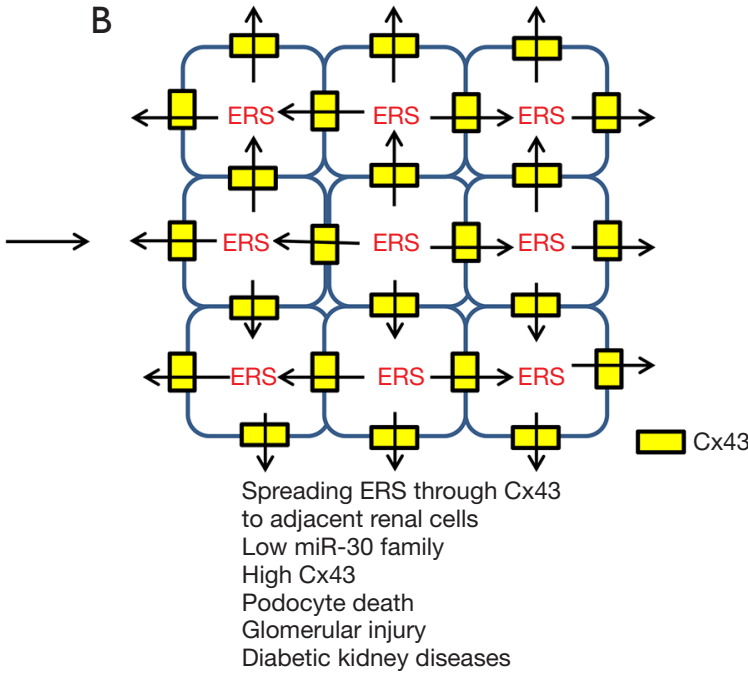

Figure 2 ERS spread from stressed single cells to multiple adjacent cells through Cx43. (A) Healthy or non-disease conditions. Even if one stressed cell exists, other cells are not affected (healthy). (B) Spreading ERS from single cell (center) to adjacent multiple cells through Cx43 increased in diabetic conditions. Please read the main text for more details. ERS, endoplasmic reticulum stress; Cx43, connexin 43.

are regulated by target RNA (Serpin1) (25). Therefore, miR-30s may also be regulated by the other target RNAs such as Cx43 mRNA which is potentially transmitted from stressed cells to destroy miR-30s in healthy cells.

Identifying new therapeutic targets for DKD is crucial now. As shown in the recent study (12), intercellular transmission of ERS through Gap Junction targeted by miR-30s may be a new key step of DKD. miRNA studies provided us numerous unexpected discoveries. Controlling such miRNAs using the knowledge obtained from the study 
on RNA biogenesis might provide new effective ways to treat or prevent the disease progression in the future.

\section{Acknowledgments}

Funding: Partially supported by the Wanek Family Project for the Cure of Type 1 diabetes.

\section{Footnote}

Provenance and Peer Review: This article was commissioned by the editorial office, Annals of Translational Medicine. The article did not undergo external peer review.

Conflicts of Interest: The author has completed the ICMJE uniform disclosure form (available at http://dx.doi. org/10.21037/atm-21-1280). The author has no conflicts of interest to declare.

Etbical Statement: The author is accountable for all aspects of the work in ensuring that questions related to the accuracy or integrity of any part of the work are appropriately investigated and resolved.

Open Access Statement: This is an Open Access article distributed in accordance with the Creative Commons Attribution-NonCommercial-NoDerivs 4.0 International License (CC BY-NC-ND 4.0), which permits the noncommercial replication and distribution of the article with the strict proviso that no changes or edits are made and the original work is properly cited (including links to both the formal publication through the relevant DOI and the license). See: https://creativecommons.org/licenses/by-nc-nd/4.0/.

\section{References}

1. Kanwar YS, Sun L, Xie P, et al. A glimpse of various pathogenetic mechanisms of diabetic nephropathy. Annu Rev Pathol 2011;6:395-423.

2. Forbes JM, Cooper ME. Mechanisms of diabetic complications. Physiol Rev 2013;93:137-88.

3. Reidy K, Kang HM, Hostetter T, et al. Molecular mechanisms of diabetic kidney disease. J Clin Invest 2014;124:2333-40.

4. Kato M, Natarajan R. Epigenetics and epigenomics in diabetic kidney disease and metabolic memory. Nat Rev Nephrol 2019;15:327-45.

5. Cybulsky AV. Endoplasmic reticulum stress, the unfolded protein response and autophagy in kidney diseases. Nature Reviews Nephrology 2017;13:681.

6. Taniguchi M, Yoshida H. Endoplasmic reticulum stress in kidney function and disease. Curr Opin Nephrol Hypertens 2015;24:345-50.

7. Kato M, Wang M, Chen Z, et al. An endoplasmic reticulum stress-regulated lncRNA hosting a microRNA megacluster induces early features of diabetic nephropathy. Nature Communications 2016;7:12864.

8. Bartel DP. Metazoan MicroRNAs. Cell 2018;173:20-51.

9. Kato M. Noncoding RNAs as therapeutic targets in early stage diabetic kidney disease. Kidney research and clinical practice 2018;37:197-209.

10. Trionfini P, Benigni A, Remuzzi G. MicroRNAs in kidney physiology and disease. Nat Rev Nephrol 2015;11:23-33.

11. Badal SS, Danesh FR. MicroRNAs and their applications in kidney diseases. Pediatric Nephrology 2015;30:727-40.

12. Li M, Ni W, Zhang M, et al. MicroRNA-30/Cx43 axis contributes to podocyte injury by regulating ER stress in diabetic nephropathy. Ann Transl Med 2020;8:1674.

13. Kumar NM, Gilula NB. The gap junction communication channel. Cell 1996;84:381-8.

14. Mittelbrunn M, Sánchez-Madrid F. Intercellular communication: diverse structures for exchange of genetic information. Nature Reviews Molecular Cell Biology 2012;13:328-35.

15. Abed A, Toubas J, Kavvadas P, et al. Targeting connexin 43 protects against the progression of experimental chronic kidney disease in mice. Kidney International 2014;86:768-79.

16. Yuan D, Li X, Luo C, et al. Inhibition of gap junction composed of $\mathrm{Cx} 43$ prevents against acute kidney injury following liver transplantation. Cell Death \& Disease 2019;10:767.

17. Prakoura N, Kavvadas P, Chadjichristos CE. Connexin 43: a New Therapeutic Target Against Chronic Kidney Disease. Cellular Physiology and Biochemistry 2018;49:985.

18. Yaoita E, Yao J, Yoshida Y, et al. Up-Regulation of Connexin43 in Glomerular Podocytes in Response to Injury. The American Journal of Pathology 2002;161:1597-606.

19. Tirosh A, Tuncman G, Calay ES, et al. Intercellular Transmission of Hepatic ER Stress in Obesity Disrupts Systemic Metabolism. Cell Metabolism 2021;33:319-33.e6.

20. Ameres SL, Horwich MD, Hung J-H, et al. Target RNADirected Trimming and Tailing of Small Silencing RNAs. Science 2010;328:1534-9. 


\section{Page 4 of 4}

21. Pasquinelli AE. Paring MiRNAs Through Pairing. Science 2010;328:1494-5.

22. Kato M. Target RNA-directed microRNA degradation; which controls which? Noncoding RNA Investig 2018;2:62.

23. Han J, LaVigne CA, Jones BT, et al. A ubiquitin ligase mediates target-directed microRNA decay independently of tailing and trimming. Science 2020;370:eabc9546.

Cite this article as: Kato $M$. Intercellular transmission of endoplasmic reticulum stress through gap junction targeted by microRNAs as a key step of diabetic kidney diseases? Ann Transl Med 2021;9(10):827. doi: 10.21037/atm-21-1280

\section{Kato. ERS through Cx43 targeted by microRNAs in DKD}

24. Shi CY, Kingston ER, Kleaveland B, et al. The ZSWIM8 ubiquitin ligase mediates target-directed microRNA degradation. Science 2020;370:eabc9359.

25. Ghini F, Rubolino C, Climent M, et al. Endogenous transcripts control miRNA levels and activity in mammalian cells by target-directed miRNA degradation. Nat Commun 2018;9:3119. 